\title{
Development of Differential Diagnosis Scale Items for Adductor Spasmodic Dysphonia and Evaluation of Clinical Availability
}

\author{
Jae Kyung Cho ${ }^{1}$, Seong Hee Choi $^{2}$ (D) Sang Hyuk Lee ${ }^{1}$ (D) and Sung Min Jin ${ }^{1}$ (D) \\ 'Department of Otorhinolaryngology-Head and Neck Surgery, Kangbuk Samsung Hospital, Sungkyunkwan University School of Medicine, \\ Seoul, Korea \\ ${ }^{2}$ Department of Audiology and Speech-Language Pathology, Daegu Catholic University, Daegu, Korea
}

\section{내전형 연축성 발성장애 감별진단 문항 개발과 임상적 유용성 평가}

조재경 ${ }^{1}$, 최성희 ${ }^{2}$, 이상혁 ${ }^{1}$, 진성민 ${ }^{1}$

성균관대학교 의과대학 강북삼성병원 이비인후과학교실, ${ }^{1}$ 대구가톨릭대학교 언어청각치료학과 ${ }^{2}$

Background and Objectives The purpose of this study was to develop the differential diagnosis scale containing items from adductor spasmodic dysphonia (ADSD) to muscle tension dysphonia (MTD) and the determine clinical utility of newly developed items.

Materials and Method The four parts of pitch, redirected phonation, automatic speech and voiced sound were selected for analyzing the characteristics of ADSD in the literature. One part of tense voiceless sound was developed according to the Korean manner of articulation. The content validity was evaluated based on 5 scales (1-5 point) analysis from 30 experts. One hundred patients (50 ADSD and 50 MTD) were recorded in reading a sentence and sustained phonation. The two speech language pathologist evaluated recorded voices through a blind test using 4 scales (0-3 point) for newly developed items.

Results As a result of verifying the content validity of items with experts, it was identified that the differentiated items were valid with 4.2 out of 5 . Through the differential diagnosis between two groups according to the items, the correlation between sub-domains and total scores was shown as higher than 0.710 . The result of analyzing the reliability on each diagnosis domain was $0.840-0.893$, which showed the internal consistency of items was great. Newly developed five parts of ADSD were significantly higher than those of MTD with strong correlation $(p<0.01)$. The reliability among the evaluators was analyzed as high with 0.892 .

Conclusion In this study, the differential diagnosis scale of ADSD was revealed as having validity and reliability. It is considered that it will be useful for differentiating ADSD and MTD in the clinical field.

Keywords Adductor spasmodic dysphonia; Muscle tension dysphonia; Diagnosis; Validity; Reliability.
Received November 15, 2019

Revised November 25, 2019

Accepted December 7, 2019

Corresponding Author Sang Hyuk Lee, MD

Department of Otorhinolaryngology-

Head and Neck Surgery,

Kangbuk Samsung Hospital,

Sungkyunkwan University

School of Medicine,

29 Saemunan-ro, Jongno-gu,

Seoul 03181, Korea

Tel +82-2-2001-2269

Fax+82-2-2001-2273

E-mail entlsh@hanmail.net

\section{ORCID iDs}

Jae Kyung Cho (DD

https://orcid.org/0000-0001-8530-1774 Seong Hee Choi (D)

https://orcid.org/0000-0003-2365-6187

Sang Hyuk Lee (D)

https://orcid.org/0000-0003-4412-3486

Sung Min Jin (i)

https://orcid.org/0000-0003-0714-5862

This is an Open Access article distributed under the terms of the Creative Commons Attribution Non-Commercial License (https://creativecommons.org/ licenses/by-nc/4.0) which permits unrestricted non-commercial use distribution, and reproduction in any medium, provided the original work is properly cited. 


\section{서 론}

내전형 연축성 발성장애(adductor spasmodic dysphonia, $\mathrm{ADSD})$ 는 운동 유발성 근육 이상증으로 그 원인은 명확히 알려져 있지 않으나, ${ }^{1,2)}$ 성대 내근의 불수의적인 수축으로 인 하여 갑작스럽게 발성 일탈, 쥐어짜는 목소리, 음성 진전 등 의 음성 특징이 나타난다. 통상적인 치료는 보튤리눔 독소 주입술(botulinum toxin injection)이 주로 시행되며, 음성 치료를 병행하여 안정된 발성을 이끌 수 있다고 보고된다. ${ }^{3)}$ 근긴장성 발성장애(muscle tension dysphonia, MTD)는 후 두에 뚜렷한 구조적 혹은 신경학적 이상이 없이 후두 근육의 과도한 긴장에 의해 발생하며) 음성의 오용과 남용으로 해 부학적이나 신경학적인 후두 구조는 정상이지만 지나친 근긴 장으로 병리적인 음성이 나타난다. ${ }^{4.5)}$ 발성의 경우 내전형 연 축성 발성장애의 음성과 유사한 특징을 보이는데 치료는 후 두 마사지와 음성 치료가 근간이 된다. ${ }^{5)}$ 두 질환은 증상이 유사하나 치료 방법이 서로 상이하기 때문에 감별진단이 정 확하고 분명하게 이루어져야 한다.

내전형 연축성 발성장애를 감별하기 위해서 모음 연장발성, 유성음 문장 읽기, 노래 부르기, 웃기, 속삭이기 등을 통해 발 성 양상을 관찰하기도 한다. ${ }^{6}$ 현재까지 내전형 연축성 발성장 애를 객관적으로 감별하는 방법이 제시되지 않아 각 병원마 다 발화 과제 시의 음성 끓김의 여부와 청지각적인 특성에 의 존하여 그 감별진단이 이루어지고 있다. ${ }^{4)}$ 그렇기에 우리나라 현실에 맞게 간편하고 정확하게 실시할 수 있는 감별검사의 개발이 필요한 실정이다.

현재까지 연구된 내전형 연축성 발성장애의 특성에서 가성 발성 시 평상시 목소리보다 음질이 좋아지는 점ㄱㄱㄱㅘ 웃을 때 나 노래할 때 쥐어짜거나 노력형 목소리가 감소하는 것을 살 펴볼 수 있으며,) 유성음 문장 발화 시 음성 끊김, 발성 일탈이 빈번하게 나타난다고 보고되어 있다. ${ }^{8}$ 하지만 소리의 질적 차 이가 영어권에서는 유성음과 무성음의 대립이 있는 반면 한 국어에서는 발성 유형에 따라 평음, 격음, 경음의 대립으로 나 누어지기 때문에 우리나라 발성 유형에 맞는 발화 문구가 개 발되어야 할 필요성이 있다.

국내 연구에서는 성문의 틈(glottal gap)은 격음에서 가장 크게 나타나고 다음으로는 평음, 경음순으로 나타난다고 보 고하고 있으며,9) 성문저항은 평음, 격음보다 경음에서 제일 높 게 나타난다고 한다. ${ }^{8)}$ 이를 바탕으로 보았을 때 성대 근육이 불수의적인 수축을 하여 과내전되는 내전형 연축성 발성장애 의 발성 특징이 우리말 경음, 격음이 포함된 문장 읽기 시 두드 러지게 나타날 것으로 사료된다.

본 연구에서는 지금까지 연구된 내전형 연축성 발성장애의
음성 특성을 바탕으로 우리나라 고유의 언어적 요소에 적용 하여 음도, 생리적 발성, 자동구어, 유성음, 경음격음 총 5 가지 영역으로 나누어 문항 개발을 실시하였다. 또한 내전형 연축성 발성장애와 근긴장성 발성장애로 진단받은 환자들을 대상으 로 개발된 내전형 연축성 발성장애 감별진단 문항의 유용성 에 대해 알아보고자 하였다.

\section{대상 및 방법}

검사 문항은 국내외 연구되었던 내전형 연축성 발성장애의 음성 특징을 참고하여 검사 문항을 만들었으며, 이 중 공통적 으로 언급되거나 변별력이 높다고 생각되는 문항을 선정하였 다. 또한 추가적인 문항들에 대해서는 전문가들과의 자문 회 의를 통해 국내 현실에 적합한 문항을 개발하였다(Table 1) (Appendix).

검사 영역으로는 음도, 생리적 발성, 자동구어, 유성음, 경음 격음 총 5 가지로 음도 영역의 경우 평상시 /a/ 연장발성, 가성 으로 /a/ 연장발성, 저음으로 /a/ 연장발성으로 나누었으며, 생리적 발성 영역에서는 하품-한숨과 웃기, 자동구어 영역에 서는 노래 부르기와 숫자 세기, 유성음 영역과 경음격음 영역 에서는 문장과 일상생활 구어로 문항을 11 가지로 세분화하였 다. 세분화된 문항을 바탕으로 이비인후과 전문의 10 명, 이비 인후과 언어재활사 10 명, 언어치료학과 교수 10 명 총 30 명의 전문가들에게 5점 리커드 척도를 기반으로 설문조사를 시행 하였다. 각 문항의 점수는 '1점: 매우 적절하지 않음, 2점: 적절 하지 않음, 3점: 보통, 4점: 적절함, 5점: 매우 적절함'으로 설정 하여 타당도를 조사하였다.

새로 개발된 검사 문항의 임상적 유용성을 확인하기 위하 여 2017년 1월 2019년 2월까지 본원 이비인후과를 내원하여 전반적인 음성평가를 통해 이비인후과 전문의와 언어재활사 에 의해 내전형 연축성 발성장애와 근긴장성 발성장애로 진 단받은 총 100명을 대상으로 하였다(IRB File No. 2018-08019-008). 대상자 모두 여성으로 내전형 연축성 발성장애군은 50 명이며 평균 나이는 35.7 세, 근긴장성 발성장애군은 50 명으 로 평균나이는 53.2세였다.

모든 녹음된 데이터는 무선 배치 후 2 인의 언어재활사가 청 지각적 평가를 진행하였으며, 두 질환 간의 검사 채점 방법은 0 3점까지 4점 척도로 음성 떨림, 음성 일탈, 쥐어짜는 목소 리, 힘이 들어가는 목소리 중에 '0점: 전혀 나타나지 않음, 1점: 1 개 이상이 나타났으나 매우 드물게 나타남, 2점: 1 개 이상이 대부분 나타남, 3 점: 1 개 이상이 항상 나타남으로 평가하였다. 반면 음도 영역의 가성으로 /a/ 연장발성과, 생리적 발성 영역, 자동구어 영역에서는 음질이 좋아지는 내전형 연축성 발성장 
애의 음성 특징을 고려하여 채점 방법을 역순으로 점수를 설 정하였다. 검사-재검사 신뢰도를 알아보기 위해 환자군 $10 \%$ 에 해당하는 10 명을 대상으로 1차 검사일로부터 2주 이내 1회 의 재검사를 추가로 실시하였으며 신뢰도는 $95 \%$ 였다. 총 5 가 지 영역의 청지각적 평정은 각 항목 별로 점수를 합한 후 평균 값을 비교하였다.

수집된 자료는 통계분석 프로그램 Statistical package for the social sciences(SPSS, version 12.0, SPSS Inc., Chicago, $\mathrm{IL}, \mathrm{USA}$ )로 분석하였다. 각 항목에 대하여 두 집단 간의 차 이는 독립 표본 $\mathrm{t}$-검증(independent sample t-test)을 실시 하였고 통계 검정상 $\mathrm{p}<0.05$ 를 유의한 것으로 간주하였다. 평 가자 간 신뢰도와 검사-재검사 간의 신뢰도를 측정하기 위해 피어슨 상관계수(Pearson r correlation)로 분석하였다.

\section{결 과}

전문가들에게 문항의 내용타당성 검증을 한 결과, 5점 만점 에 4.2점을 받아 해당 문항이 타당한 것을 확인하였다. 내전 형 연축성 발성장애 감별검사의 하위 영역과 총점과의 상관은 0.710 이상으로 높게 나타났으며, 각 하위 영역 간에는 0.319 0.720 의 상관을 보였다(Table 2). 문항 내적 일관성을 측정하 였을 때 5개의 영역의 신뢰도는 0.840 0.893로서 비교적 높 은 것으로 나타났다. 신뢰도가 가장 높은 영역은 음도 영역이 며, 가장 낮은 영역은 생리적 발성 영역으로 분석되었다.
내전형 연축성 발성장애 감별진단 5 가지 영역을 분석한 결 과(Table 3), 모든 영역에서 두 집단 간의 유의한 차이를 보였 다. 5가지 영역별로 결과를 살펴보면 내전형 연축성 발성장 애의 '음도'는 5.38점, '생리적 발성'은 4.65점, '자동구어'는 2.50 점, '유성음'은 5.20점, '경음격음은 5.30점을 보였다. 근긴장성 발성장애의 평균 점수는 '음도'는 3.38점, '생리적 발성'은 1.28 점, '자동구어'는 0.85점, '유성음'은 4.13점, '경음격음'은 3.70점 을 나타냈다. 내전형 연축성 발성장애가 모든 요소에서 점수 가 제일 높았으며, 음도와 경음격음 영역에서 유의하게 높은 결과를 보였다. 평가자가 각각 평정한 내전형 연축성 발성장 애 감별진단 검사 문항 결과에 대해 평가자 간 신뢰도를 조사 한 결과 0.892 로 높게 나타났으며, 검사-재검사 신뢰도는 0.91 로 매우 높은 상관 결과를 보였다.

\section{고 찰}

연축성 발성장애는 후두 근육의 불수의적 수축으로 발성 시 어려움을 보이는 음성장애로 원인은 아직 확실히 밝혀져 있지 않다.,2) 연축성 발성장애는 세 가지 유형으로 나뉘어지는 데 가장 일반적으로 나타나는 내전형의 경우 불수의적인 성 대의 과내전에 의해 음성이 끊어지고 목을 조이는 듯한 목소 리가 나타난다. 그 다음으로는 갑자기 성대가 열려 바람이 새 는 듯한 목소리를 나타내거나 목소리가 산출되지 않는 외전 형과 마지막으로 두 증상을 복합적으로 가지고 있는 혼합형

Table 1. Differential diagnosis scale items for adductor spasmodic dysphonia Subtest

Prolonged phonation /a/ for 5 seconds in a normal voice

Pitch Prolonged phonation /a/ for 5 seconds in a low voice

Prolonged phonation /a/ for 5 seconds in falsetto

Redirected phonation Yawn-sigh

Laugh

Automatic speech

Singing the first verse of the Korea national anthem

Counting 1 to 10

Voiced sound

Speaking a sentence with voiced sounds in a normal voice

Speaking functional phrases in a daily life starting with a voiced sounds in a normal voice

Speaking a sentence with tense and voiceless sounds in a normal voice

Tense voiceless sound Speaking functional phrases in a daily life with tense and voiceless sounds in a normal voice

Table 2. Construct validity

\begin{tabular}{|c|c|c|c|c|c|}
\hline & Total score & Pitch & Redirected phonation & Automatic speech & Voiced sound \\
\hline Pitch & 0.746 & & & & \\
\hline Redirected phonation & 0.889 & 0.507 & & & \\
\hline Automatic speech & 0.735 & 0.411 & 0.720 & & \\
\hline Voiced sound & 0.710 & 0.379 & 0.554 & 0.319 & \\
\hline Tense voiceless sound & 0.785 & 0.649 & 0.599 & 0.541 & 0.415 \\
\hline
\end{tabular}


Table 3. Comparison of perceptual analysis between ADSD and MTD

\begin{tabular}{lll} 
& \multicolumn{1}{c}{ ADSD } & MTD \\
Pitch & $5.38 \pm 0.774^{* *}$ & $3.38 \pm 0.897$ \\
Redirected phonation & $4.65 \pm 1.21^{*}$ & $1.28 \pm 1.467$ \\
Automatic speech & $2.50 \pm .641^{*}$ & $0.85 \pm 0.834$ \\
Voiced sound & $5.20 \pm 1.159^{*}$ & $4.13 \pm 0.648$ \\
Tense voiceless sound & $5.30 \pm 0.648^{* *}$ & $3.70 \pm 0.648$ \\
\hline
\end{tabular}

Variables are presented as mean \pm standard deviation. ${ }^{*} \mathrm{p}<0.01$, ${ }^{* *} \mathrm{p}<0.001$. ADSD: adductor spasmodic dysphonia, MTD: muscle tension dysphonia

으로 구분된다.) 대부분의 환자가 내전형에 속하며 내전형 연 축성 발성장애는 발성 시에 성대가 너무 강하게 내전되어서 쥐 어짜는 듯한 음성, 음성 끊김, 비유창한 음성, 애성(hoarseness) 등의 특징적인 음성을 보인다. ${ }^{10}$

근긴장성 발성장애는 지나친 후두 근육의 긴장으로 인해 신 목소리가 나타나거나 심각한 경우 음성의 완전한 손실 등이 나타날 수 있다고도 알려져 있으며 노력성 발성 고음의 가성 발성, 음이탈 등의 증상이 나타날 수 있다. ${ }^{10)}$ 원인으로는 심리 적 또는 성격의 요인, 발성 시 후두, 턱, 혀 목 등을 포함한 근 육의 오남용, 기질적 원인에 대한 과잉 보상의 결과로 나타날 수 있다고 한다. ${ }^{5)}$

내전형 연축성 발성장애와 근긴장성 발성장애는 구조적인 성대 결함이 없으나, 성문상부의 과도한 수축으로 인해 음성 의 떨림, 쥐어짜는 목소리 등의 음성 특징을 보인다. 두 질환 의 치료 방법이 서로 다르기 때문에 정확한 감별진단이 중요 한데 내전형 연축성 발성장애에서는 보툴리눔 독소 주입술이 치료의 근간이 되고 음성 치료의 효과는 떨어진다는 점고과 근긴장성 발성장애에서는 후두 마사지, 음성 치료가 효과적이 라는 점에서 차이를 보인다.5) 두 질환에 대한 음성 특징 연구 와 함께 각 기관마다 다르게 진행되고 있는 감별검사의 통일 된 검사 시스템이 필요한 실정이다.

본 연구에서 국내외 선행 연구들을 토대로 5 가지 영역으로 개발하였으며 검사의 타당도, 신뢰도 검증과 내전형 연축성 발 성장애와 근긴장성 발성장애 영역별 점수를 비교하였다.

음도 영역에서 내전형 연축성 발성장애군이 근긴장성 발성 장애군에 비해 높은 결과를 보였으며 통계적으로 유의한 차 이가 있었다. 두 질환을 구분할 때 음도 영역의 가성 연장발 성이 기준이 되는 것을 확인할 수 있었는데 내전형 연축성 발 성장애의 경우 가성 연장발성 시 음질이 좋아지는 것을 볼 수 있었으며 이는 Cannito와 Woodson ${ }^{11)}$ 의 연구에서 가성 발성 시 음질이 좋아진다는 선행연구와 일치하였다.

생리적 발성 영역에서 내전형 연축성 발성장애군이 근긴장 성 발성장애군에 비해 높은 결과를 보였으며 통계적으로 유
의한 차이가 있었다. 이번 연구에서 내전형 연축성 발성장애 환자군에서 생리적 발성 시 음질이 훨씬 더 좋아지는 것을 확인할 수 있었으며, 마찬가지로 선행 연구와 일치하는 것을 확인할 수 있었다.

자동구어 영역에서 내전형 연축성 발성장애군이 근긴장성 발성장애군에 비해 높은 결과를 보였으며 통계적으로 유의한 차이가 있었다. 이는 기존의 Ludlow 등ㄱ) 연구에서 노래를 부 를 때 쥐어짜는 목소리, 음성 일탈이 줄어든다는 결과와 일치 하였으며, 숫자 세기의 경우 제시한 문장에 따른 과제 난이도 에 따라 음성 특징이 심하게 나타나는 것을 보았을 때 횔씬 수 행하기 쉽게 느껴져 음성 일탈과 쥐어짜는 목소리가 줄어드는 것으로 보여진다.

'여보세요., '안녕하세요.', '아니요.'와 같이 모음으로 시작하 거나 '5월 5일은 어린이날이에요.'12)와 같이 문장 전체가 유성 음으로 된 유성음 영역에서 내전형 연축성 발성장애군이 근긴 장성 발성장애군에 비해 유의하게 높은 점수를 보였다. 내전 형 연축성 발성장애의 경우 과제 의존도에 따라 수행 차이를 보이는데 Erickson ${ }^{13}$ 과 Ludlow 등ㄱㅇㅔ 의하면 연축성 발성 장애 환자군의 경우 유성음 문장을 산출할 때 음성 일탈이 빈 번하게 발생한다는 연구와 일치하였다. 반면 근긴장성 발성장 애군에서는 과제에 따른 특성 차이가 거의 없다고 하였다. ${ }^{14}$

경음격음 영역에서 내전형 연축성 발성장애군이 근긴장성 발성장애군에 비해 유의하게 높은 점수를 보였다. 특히, 내전 형 연축성 발성장애군과 근긴장성 발성장애는 유성음으로 시 작하는 문장과 비교했을 때 거의 차이가 없었으나, 경음격음 영역에서 근긴장성발성장애는 더 낮은 점수를 보였다. 이는 영어권에서 사용되는 유성음 문장보다 우리나라 발성 유형에 따라 나누어지는 경음격음을 활용하여 개발된 문구가 발화 시 조음 운동의 복잡성을 증가시키므로 성대가 불수의적으로 수축하여 발성되는 내전형 연축성 발성장애의 음성 특징을 더 잘 반영하는 것으로 보여진다. 우리말의 경우, 격음과 경음 은 무성음이지만 [-긴장성]을 보이는 평음과 달리 경음과 격 음은 [+긴장성]을 보이며, 경음은 [-기식성]을 보이는 반면, 격 음은 [+기식성]을 보이는데, 경음과 격음 문맥이 모두 긴장성 을 보이므로 $\mathrm{ADSD}$ 환자나 MTD 환자의 발성 특징인 긴장성 발성에 영향을 줄 것으로 사료된다. 또한, 격음은 [+긴장성]이 지만, [+기식성]이므로 경음에 비해 성문저항이 적으므로 경 음과 격음이 같이 있는 문맥에서는 모두 긴장성 음성을 보이 나 경음부분보다는 격음부분에서 더 많은 긴장성이 있을 수 있다. 실제로 택시[택씨:]의 경우 ' $E$ '은 격음이지만 후행 자음 인 ''이 '씨인 경음으로 발음이 되면서 환자들이 'E'보다는 'ㅆ에서 더 많은 음성진전이나 쥐어짜는 음질의 특성이 두드 러짐이 관찰되었다. '셋째' [섿째]나 '갔다' [갇따], '학교' [하꾜] 
와 같은 경우에도 격음이나 평음보다는 '째'나 '따', '꾜'와 같은 끝 부분에서 더 많은 힘이 들어가거나 긴장성 음성이 나타났 으며, '따뜻한' [따뜨탄]에서도 '따뜨'와 같은 경음문맥에서 '탄' 과 같은 격음보다 더 많은 음성진전이나 음성일탈을 보였다. 이는 우리말에서 보이는 고유한 발성 유형에 따른 자음의 특 징으로서 이러한 문맥에서의 검사어는 유/무성으로만 구분되 는 영어권의 자음과는 달리 MTD나 ADSD 환자의 발성 특징 을 검사하기에 적절할 것으로 보인다.

\section{결 론}

본 연구를 통해 내전형 연축성 발성장애와 근긴장성 발성 장애의 감별을 위한 음성 특징을 관찰했다. 개발된 검사 문항 을 통해 두 질환을 변별하기에 적합하고 유용한 것을 확인할 수 있었다. 반면 두 발성장애의 표집 수가 적었고 후향적 연구 라는 제한점이 있었다. 향후 추가적으로 대상자 및 유병 기간 등을 확보하고 검사 문항 간의 결과 상관관계에 대한 후속 연 구가 필요할 것으로 사료된다.

중심 단어: 내전형 연축성 발성장애, 근긴장성 발성장애, 진 단, 타당도, 신뢰도.

\section{Acknowledgments}

This work is supported by 2018 Capacity Development Project from The Korean Association of Speech Language Pathologists.

Conflicts of Interest

The authors have no financial conflicts of interest.

Authors' Contribution

Conceptualization: Seong Hee Choi, Sang Hyuk Lee, Sung Min Jin. Data curation: Jae Kyung Cho, Seong Hee Choi. Funding acquisition: Jae Kyung Cho. Methodology: Jae Kyung Cho. Project administration: Jae Kyung Cho. Supervision: Seong Hee Choi, Sung Min Jin. Validation: Seong Hee Choi, Sang Hyuk Lee, Sung Min Jin. Writ- ing — original draft: Jae Kyung Cho. Writing — review \& editing: Seong Hee Choi, Sang Hyuk Lee, Sung Min Jin. Approval of final manuscript: all authors.

\section{REFERENCES}

1. Aronson AE, Brown JR, Litin EM, Pearson JS. Spastic dysphonia. II. Comparison with essential (voice) tremor and other neurologic and psychogenic dysphonias. J Speech Hear Disord 1968;33(3):219-31.

2. Schaefer SD. Neuropathology of spasmodic dysphonia. Laryngoscope 1983;93(9):1183-204.

3. Blitzer A, Brin MF, Stewart CF. Botulinum toxin management of spasmodic dysphonia (laryngeal dystonia): a 12-year experience in more than 900 patients. Laryngoscope 2015;125(8):1751-7.

4. Roy N, Ford CN, Bless DM. Muscle tension dysphonia and spasmodic dysphonia: the role of manual laryngeal tension reduction in diagnosis and management. Ann Otol Rhinol Laryngol 1996;105(11):851-6.

5. Morrison MD, Rammage LA, Belisle GM, Pullan CB, Nichol H. Muscular tension dysphonia. J Otolaryngol 1983;12(5):302-6.

6. Yun YS, Kim HH, Son YI. Useful speech task in the perceptual evaluation of adductor spasmodic dysphonia. Commun Sci Disord 2003; 8(2):146-62.

7. Ludlow CL, Adler CH, Berke GS, Bielamowicz SA, Blitzer A, Bressman SB, et al. Research priorities in spasmodic dysphonia. Otolaryngol Head Neck Surg 2008;139(4):495-505.

8. Choi SH, Choi $\mathrm{CH}$. The comparison of aerodynamic measures in korean stop consonants based on phonation types. Phonetics and Speech Sciences 2014;6(4):195-203.

9. Hong KH, Kim HK, Niimi S. Laryngeal gestures during stop production using high-speed digital images. J Voice 2002;16(2):207-14.

10. Rubin JS, Sataloff RT, Korovin GS. Diagnosis and treatment of voice disorders. 4th ed. San Diego, CA: Plural Publishing;2014.

11. Cannito MP, Woodson GE. The spasmodic dysphonias. In: Kent RD, Ball MJ, editors. Voice Quality Measurement. San Diego, CA: Singular Publishing Group;2000. p.411-30.

12. Choi SH. Development of Korean standardized sentences on voice quality evaluation for dysphonia. Audiol Speech Res 2018;14(2):128-42.

13. Erickson ML. Effects of voicing and syntactic complexity on sign expression in adductor spasmodic dysphonia. Am J Speech Lang Pathol 2003;12(4):416-24.

14. Rees CJ, Blalock PD, Kemp SE, Halum SL, Koufman JA. Differentiation of adductor-type spasmodic dysphonia from muscle tension dysphonia by spectral analysis. Otolaryngol Head Neck Surg 2007;137(4): 576-81. 


\section{Appendix}

Differential Diagnosis Scale Items for Adductor Spasmodic Dysphonia

\begin{tabular}{|c|c|c|c|}
\hline & 내용 & 점수 & 채점방법 \\
\hline \multirow{3}{*}{ Pitch } & 평상시 목소리로 /a/ 5초 연장 발성하기 & & \multirow{11}{*}{$\begin{array}{l}\text { 음성 떨림, 음성 일탈, 쥐어짜는 목소리, 힘이 들어가는 목소리 중 } \\
0 \text { 점: 전혀 나타나지 않음 } \\
\text { 1점: } 1 \text { 개 이상이 나타났으나, 매우 드물게 나타남 } \\
\text { 2점: } 1 \text { 개 이상이 대부분 나타남 } \\
\text { 3점: } 1 \text { 개 이상이 항상 나타남 }\end{array}$} \\
\hline & 낮은 목소리로 /a/ 5초 연장 발성하기 & & \\
\hline & 가성으로 /a/ 5초 연장 발성하기 & & \\
\hline \multirow{2}{*}{$\begin{array}{l}\text { Redirected } \\
\text { phonation }\end{array}$} & 깊게 하품-한숨 뒤 소리내기 & & \\
\hline & 웃음 유도하기 & & \\
\hline \multirow{2}{*}{$\begin{array}{c}\text { Automatic } \\
\text { speech }\end{array}$} & 애국가 첫 소절 부르기 & & \\
\hline & 1 에서 10 까지 숫자 세기 & & \\
\hline \multirow{2}{*}{$\begin{array}{l}\text { Voiced } \\
\text { sound }\end{array}$} & $\begin{array}{l}\text { 평상시 목소리로 } \\
\text { 유성음 문장(5월 5일은 어린이날이에요)을 말하기 }\end{array}$ & & \\
\hline & $\begin{array}{l}\text { 평상시 목소리로 유성음으로 시작하는 } \\
\text { 일상생활 구어(여보세요, 안녕하세요, 아니요) 말하기 }\end{array}$ & & \\
\hline \multirow{2}{*}{$\begin{array}{c}\text { Tense } \\
\text { voiceless } \\
\text { sound }\end{array}$} & $\begin{array}{l}\text { 평상시 목소리로 경음격음이 포함된 } \\
\text { 문장(셋째 날 학교에서 소풍을 갔다) 말하기 }\end{array}$ & & \\
\hline & $\begin{array}{l}\text { 평상시 목소리로 경음격음이 포함된 } \\
\text { 일상생활 구어(택시, 따뜻한 아메리카노) 말하기 }\end{array}$ & & \\
\hline
\end{tabular}

